\title{
Cuando se vive el desarraigo. Educación y desplazamiento forzado: una mirada desde el Distrito de Aguablanca, Cali, Colombia*
}

\section{When you Live the Uprooting. Education and Forced Displacement: A Look From the District of Aguablanca, Cali, Colombia.}

\section{Patricia Lasso Toro}

Referencia para citar este artículo: LASSO TORO, P. (2013). "Cuando se vive el desarraigo. Educación y desplazamiento forzado: una mirada desde el Distrito de Aguablanca, Cali, Colombia”. En: Revista Guillermo de Ockham 11(2). pp. 35 - 51.

\section{Resumen}

El presente artículo identifica las circunstancias que afectan la población en situación de desplazamiento cuando ingresan al sistema escolar en el Distrito de Aguablanca (DAB) en la ciudad de Cali; el estudio se soporta por medio de la investigación acción participación (IAP). Durante la primera fase exploratoria del estudio se llevaron a cabo ocho sesiones de grupos focales con agentes educativos locales y se hizo observación participante en una institución educativa oficial de la ciudad. También se trabajó en mesas redondas con representantes del sistema educativo y una ONG local. Se halló que, pese a algunos esfuerzos, no es clara para las instituciones educativas la manera de atender adecuadamente a los estudiantes en situación de desplazamiento forzado. Hay un desconocimiento frente a los derechos, los aspectos psicosociales, la asistencia y a la atención en el ámbito escolar de los desplazados. Se propone llevar a cabo procesos continuos y sostenidos de formación con las instituciones educativas que faciliten la inclusión escolar de dicha población e identificar situaciones de traumatismo, asuntos de identidad cultural e interacción con el sistema educativo.

Palabras clave: educación, desplazamiento, forzado, formación, docentes, Cali, Colombia.

- Fecha de recepción del artículo: 26-08-2013 • Fecha de aceptación: 18-10-2013

PATRICIA LASSO TORO. Magíster en Educación, psicóloga, docente de la Universidad de San Buenaventura Cali. Correo electrónico: plasso@ usbcali.edu.co.

Artículo de investigación científica y tecnológica resultado del proyecto: Memorias, identidades y poblamiento en el Distrito de Aguablanca. Desplazados y territorialidad en Cali, Colombia, ejecutado por la Universidad de San Buenaventura Cali en el marco del macroproyecto Prevención de riesgos asociados a los desplazamientos de población. Definir modelos de acción educativa, promovido y coordinado por el CCI- FIUC con la participación de las universidades Uganda Martyrs University (Uganda); Institut Catholique de Kabgayi (Ruanda); Don Bosco Technical School (Camboya); Christ University (India); Ateneo de Manila University (Filipinas); Université Notre-Dame d'Hait (Haití); Assumption University (Tailanda) y las Universidades Santo Tomás y Católica de Colombia. El equipo de investigación interdisciplinar de la Universidad de San Buenaventura Cali está coordinado por el historiador Helwar H. Figueroa Salamanca, Ph.D y cuenta con investigadores de diferentes disciplinas de las Ciencias Sociales y Humanas. Además, se ejecuta en convenio con la ONG local Fundación Paz y Bien ubicada en el Distrito de Aguablanca, Cali, Valle del Cauca, Colombia (2012-2015). 


\section{Abstract}

This paper identifies the circumstances affecting the population in displacement when they arrive at schoolsystem in the District of Aguablanca, in the city of Cali. The study is supported by the Participation Action Research (PAR). During the exploratory phase of the study were conducted 8 sessions of focus groups with local education agents. Participant observation was made at a formal educational institution in the city and also worked in roundtables with representatives of the education system, and a local ONG. It was found that despite some efforts, it is not clear to educational institutions how to properly care for the students in a situation of forced displacement. There is misunderstanding over the rights to the psychosocial aspects, care and attention in the school of the displaced. It is proposed to carry out continuous and sustained process with educational training, which provides school inclusion of such a population, recognizing trauma situations, issues of cultural identity and interaction with the educational system.

Keywords: Education, forced displaced, personnel training, Cali, Colombia.

\section{Introducción}

Es por todos conocido que en las plantas la raíz es la encargada de fijarla al suelo, absorber los nutrientes necesarios para su crecimiento y proveerla de sustancias de reserva. Para "fijar" la planta al suelo, interviene una combinación de factores propios de la planta con las condiciones del suelo donde pretende arraigarse y el medio que intenta habitar. Este proceso de asentamiento de la vida no se produce solo; tal consolidación es un enlace de acontecimientos los cuales posibilitan o bien limitan la adherencia de la raíz. Si esta se fija fuertemente al suelo -como es de esperarse- desarrollará unas ramificaciones para conectarse tanto a la tierra donde se afirma, como a un entretejido con otras plantas, lo cual las ayudará a sostenerse conjuntamente. Es decir, si arrancamos una planta no solo esta sufrirá daños sino también las otras plantas, cuyas raíces secundarias se habían adherido en el tejido subterráneo.

En la sociedad humana, actos de esta naturaleza tienen similares consecuencias. El desplazamiento forzado como desarraigo ${ }^{1}$ amenaza la vida, la memoria, la identidad y las redes entretejidas como raíces afianzadas a la tierra.

Con el símil de la botánica, la raíz, la planta y sus tejidos interdependientes, se presenta este artículo el cual busca evidenciar el desarraigo vivido por las personas en condición de desplazamiento forzado al llegar a la ciudad y en particular las dificultades de este desarraigo en el contexto de la educación.

Este escrito asume el desplazamiento forzado en Colombia en coincidencia con Pizarro y Jiménez (2008); Bello, M.N (2003) y Muńoz (2008), quienes en sus investigaciones reconocen el origen histórico, recurrente y endémico del desplazamiento forzado de la población colombiana, la cual se ve obligada a salir de sus territorios originarios por causas asociadas a la lucha por el control de territorios con fuerte presencia de los múltiples actores armados ilegales que han operado históricamente en el país y la apropiación de territorios ricos en recursos naturales con alto potencial de explotación y comercialización para los intereses capitales privados, lo cual ocasiona desplazamientos espoleados por el uso de la intimidación y las acciones violentas ejecutadas por múltiples actores armados. Según esta mirada, el desplazamiento forzado opera como una estrategia violenta de dominación y control para la apropiación de tierras que ha afectado principalmente a la población campesina, indígena y afrocolombiana, según lo planteado por el Centro de Memoria Histórica (2013); Molano (2001y 2003) y Codhes (2011).

Esta definición sobre el desplazamiento forzado coincide con los planteamientos globales del macro

1. En particular en el texto se reconoce la distinción de Molano (2003) sobre el desplazamiento y el desarraigo. Para el autor, el término desplazados es robado de la física (en sus propias palabras), según el cual se "vende" la idea del desplazamiento como un simple fenómeno de traslado de un lugar a otro sin tener en cuenta las dimensiones históricas, políticas, humanas y éticas contenidas en él. La categoría desarraigo toca directamente la causa del problema: el asunto de las distintas formas de presión para obligar a la población a abandonar sus territorios y con ellos sus relaciones, sus dinámicas, su familia y su cultura con fines de la apropiación y concentración de la tierra. Este escrito reconoce esa distinción del autor y considera el asunto del desarraigo como algo que pone en evidencia esa ruptura tras la llegada de la población a la ciudad y cómo esta se revela en el sistema educativo particularmente. Al hablar de desplazamiento se enfatiza en que es forzado y contiene en su complejidad las condiciones del desarraigo. 
proyecto que coordina la CCI-FIUC y del cual esta investigación hace parte. No obstante, dadas las características de los países participantes es evidente que en África los desplazamientos están más asociados a enfrentamientos étnicos (religiosos y nacionalistas); en India a la construcción intensiva de represas y en Filipinas y Haití a los desastres naturales. Los desplazamientos en Tailandia y Camboya, a pesar de que en última instancia son producto principalmente de los problemas económicos, en sus orígenes estaban asociados al conflicto político, lo cual los pone en condiciones de afinidad con el caso colombiano. Pese a estas diferencias, todas las causas del desplazamiento terminan por cruzarse lo que dificulta grandemente su prevención; aún más, en la actualidad colombiana es evidente que se están presentando desplazamientos interurbanos y extraurbanos que se suman a las oleadas de desplazamientos forzados de origen rural.

El presente texto es fruto del proyecto de investigación Memorias, identidades y poblamiento en el Distrito de Aguablanca. Desplazados y territorialidad en Cali, Colombia ${ }^{2}$, el cual reconoce, entre otros asuntos, que el desplazamiento forzado, además de las fuertes implicaciones sociales, políticas, económicas y psicológicas que conlleva para las víctimas y las sociedades mismas implica a su vez cuestionamientos y desafíos al sistema escolar.

El artículo invita a reflexionar críticamente el asunto de la educación en relación con el desplazamiento forzado, para lo cual tiene en cuenta variables como el ingreso al sistema escolar en términos de las dificultades existentes para que se reconozca a los desplazados como víctimas al hacer los trámites correspondientes para acceder a los programas estatales, los aspectos psicosociales y culturales en juego y el papel de los educadores y los programas de asistencia escolar dirigidos a la población desplazada.
Se propone al lector como punto de partida, situarse en el escenario del trabajo de campo de la investigación: el Distrito de Aguablanca, Cali, Colombia, epicentro representante de los esfuerzos de autogestión y de la solidaridad comunitaria y popular y a su vez, de las fallas estructurales del sistema que reflejan una marginalidad sociopolítica y económica ocasionada por la falta de una presencia efectiva del Estado. No obstante (o quizá por lo mismo) cuenta con un gran potencial humano capaz de solidarizarse con el otro a partir de múltiples esfuerzos.

\section{El asentamiento en el territorio. Aguablanca: escenario de múltiples ramificaciones}

Retomando el símil biológico, vemos que raíces tienen la capacidad (de acuerdo con el grado de vitalidad de la raíz principal) de ramificarse continuamente, es decir, de formar nuevas raíces a fin de buscar en las capas inferiores del suelo más agua y nutrientes con posibilidades de ser absorbidos. Siguiendo esta metáfora, el Distrito de Aguablanca es un escenario en el cual oleadas de seres humanos desplazados intentan formar nuevas ramificaciones que les permitan reconstruir sus orígenes y tradiciones en una ciudad que se muestra agreste y excluyente.

Hace más de una década, para llegar al $\mathrm{DAB}^{3}$ era necesario tomar cerca de tres buses hasta la Autopista Sur y desde allí entrar al distrito. En ese entonces, esta zona de la ciudad se caracterizaba por sus calles polvorientas, poco desarrollo urbanístico, casas a medio hacer y la presencia de una gran cantidad de nińos en las calzadas. Hoy, sus calles en gran medida han sido asfaltadas fruto de aquello que no se muestra en los diarios y los entes estatales no reconocen: los esfuerzos de sus pobladores por intentar asentarse dignamente en un territorio poblado a través de la autocons-

2. En la recolección de información para el proyecto se contó con la colaboración de distintas personas y entidades, pero en particular se agradece a los docentes participantes del Diplomado Memoria, Educación y Desplazamiento, el cual a su vez se convirtió en un ejercicio de grupo focal del proyecto; a la Ciudadela Educativa Nuevo Latir, especialmente a su rector Hugo Alberto Lozano; a la psicóloga María Alejandra Gutiérrez y a los docentes Sofía Carpio y William Castrillón, sin olvidar a los estudiantes de Psicología de la USB Cali, Angie Mayté Peñuela, Katherine López, Viviana Hurtado y Rubén Darío Valencia.

3. El Distrito de Aguablanca es una zona de Cali conformada por tres comunas y treinta y nueve barrios que en el 2010 contaba con una población de 686.229 personas, en su gran mayoría afrodescendientes, aunque también hay presencia de indígenas, gitanos y mestizos. Este importante sector de la ciudad, además de ser un valioso conglomerado intercultural, es el lugar donde arriba el mayor número de población en condición de desplazamiento. Con respecto a su poblamiento, ver el artículo de Jesús Darío González (2012) referido al final del texto. 
trucción y el trabajo comunitario. Hoy, muchas de esas vías se han convertido en nuevas rutas que se extienden para ser ocupadas por nuevos habitantes (gran parte nómadas) víctimas del conflicto armado, quienes llegan a la casa de algún conocido, pariente o amigo con la esperanza de encontrar un lugar donde sembrar nuevamente sus raíces desarraigadas. "Cali es la ciudad más grande del suroccidente colombiano y por su localización es el sitio donde más fácilmente llegan personas de los departamentos de Cauca, Nariño y Chocó. Para las personas en situación de desplazamiento hay puntos de referencia, probablemente dados por familiares o amigos, que se localizan en la zona de ladera o en Aguablanca, los sectores de mayor vulnerabilidad y marginalidad de la ciudad" (Torres, L., en Hernández, 2009).

Su vida se suspende en ese "tránsito-corredor" hacia nuevas búsquedas muchas veces largas y fatigantes, con la esperanza de un retorno pero con la obligación de adaptarse a los nuevos territorios 4 . Entre los departamentos de origen se encuentran Cauca, Antioquia, Nariño (sobre todo de la zona costera del Pacífico colombiano), Putumayo y Cundinamarca.

En el municipio de Santiago de Cali se manifiesta el impacto del desplazamiento en las dos dimensiones del fenómeno: de un lado, en una aparentemente baja proporción se presenta el caso de la expulsión de personas y hogares, y del otro de la recepción de la población desplazada, siendo Cali la tercera ciudad receptora del país. A 31 de diciembre de 2010 se encuentran en la categoría de incluidos 77.934 personas en situación de desplazamiento forzado por el conflicto armado, de los cuales 41.060 son mujeres y 36.874 son hombres (Alcaldía de Santiago de Cali, Desepaz, 2011-2013, p.14).
Cuando se es amenazado y expulsado hay que huir para salvar la vida; pensar a dónde ir, dónde dormir y qué comer; atender al niño o a la niña que llora incansablemente; a la abuela o al abuelo enfermo. Se requiere solucionar una y mil cosas a la vez siempre con la incertidumbre de no lograrlo y la zozobra. No queda tiempo para recordar ni para sentir dolor o tristeza ${ }^{5}$. Al llegar al sitio de refugio se hace necesario afiliarse a un programa para recibir las ayudas estatales y tener servicios de salud. En este sentido, es preciso saber cómo afiliarse $^{6}$, tener dinero para transportarse, saber cómo preguntar, cómo orientarse o simplemente tener la capacidad de caminar por unas calles desconocidas y peligrosas. Es decir, se trata de solucionar cómo sobrevivir día a día sin desfallecer en el intento. Afortunadamente, en Aguablanca hay instituciones como la Fundación Paz y Bien que acompañan a los desplazados y solidariamente crean distintos programas que intentan mitigar las vicisitudes vividas tras la expulsión.

Evidentemente, frente a esta incertidumbre la educación pasa a un segundo plano: "[...] en este momento es más importante comer que ir a la escuela" dice un habitante. Sin embargo, ella es un factor clave en la reorganización de la existencia en la ciudad y en el afianzamiento al nuevo territorio. En ese esfuerzo las personas en situación de desplazamiento se encuentran en situaciones como las que se describen a continuación.

\section{El sistema escolar en el Distrito de Aguablanca. Una mirada panorámica}

En Cali se presenta un fenómeno particular en relación con la situación nacional de la edu-

4. De hecho, en un estudio llevado a cabo por la Arquidiócesis y Codhes (1996) en relación con las expectativas de permanencia, reubicación o retorno de los desplazados en Cali, se encontró que el $72 \%$ de ellos afirmaba querer quedarse en Cali, a diferencia del $14 \%$ que prefería irse a otro lugar, el $10 \%$ retornar y un $4 \%$ que no respondió. Las expectativas de permanencia, retorno o renunciación tienen relación con las necesidades más importantes de los desplazados en cuanto a generación de ingresos se refiere. Quedarse en Cali es la decisión de la inmensa mayoría (71 \%) ya que se ve como una opción de seguridad frente a la violencia de las zonas de las cuales fueron expulsados (ver: http://www.derechos.org/nizkor/colombia/desplazados/cali.html).

5. Lima L., (2000) citando a Bello MN, expone el impacto ocasionado a raíz de la procedencia campesina de los desplazados pertenecientes usualmente a culturas tradicionales caracterizadas por fuertes redes de relaciones y una marcada identidad social, a diferencia de los contextos urbanos donde predomina el individualismo, la fragmentación y la ausencia de integración. Esto conduce a que la identidad personal y social de los desplazados sufra modificaciones. "Sus derechos son vulnerados y los desplazados pierden control sobre sus vidas. Prevalece la incertidumbre y la duda. Su cotidianidad es modificada en forma abrupta. La inestabilidad se instala y en consecuencia no hay posibilidades inmediatas de reconstruir proyectos estables de vida". (p.2) Del mismo, modo Slaikeu citado en Millán (s.f) señala que uno de los aspectos más evidentes de la crisis consiste en la alteración emocional y el desequilibrio experimentado, acompańados por sentimientos de cansancio, desamparo, inadecuación, confusión, ansiedad y dificultades en el funcionamiento familiar y laboral así como muchos síntomas físicos. Otro efecto de esta desorganización es la reducción de la capacidad para defenderse, lo cual los expone a condiciones de vulnerabilidad emocional y física. De allí que se haya producido un incremento de enfermedades producto de esta situación.

6. Se hace referencia a la oficina regional de la Unidad Integral de Atención de Víctimas (UAIV), (antes UAO). 
cación (más acentuado en el DAB y en la zona de ladera) ligado a un modelo que comporta la cesión del Estado de la responsabilidad de educar a sus ciudadanos a los particulares. En efecto, el número de instituciones educativas oficiales no alcanza a cubrir las demandas de la población y el Estado suple esta deficiencia mediante instituciones educativas privadas (o mixtas) a las cuales les aporta un valor por estudiante similar al costo en el sistema oficial. Por cierto, Cali es la ciudad del país que presenta la mayor tasa de contratación educativa con colegios privados que equivale a más de la mitad de la matrícula oficial (Cámara de Comercio de Cali y otros, 2010).

¿Qué significa tener la mayor cantidad de cupos escolares del Distrito en instituciones educativas de cobertura? Para comprender esta cuestión es necesario remontarse a las dinámicas de poblamiento en el DAB. Las condiciones de territorialización dan cuenta de diversas oleadas generadas por distintos procesos migratorios (no solo por violencia sociopolítica, aunque sí en gran medida) ${ }^{7}$, que reflejan falta de planificación urbanística y de estrategias de poblamiento informal. A partir de la lucha por la vida y el asentamiento digno se han generado formas de organización social y comunitaria en las cuales tardíamente aparece el Estado para rectificarlas o consolidarlas (González, 2012).

Estas formas de organización comunitaria y de autogestión permitieron a sus habitantes construir sus casas, pavimentar calles y demandar la construcción de hospitales, escuelas, salones comunales, iglesias y parques. Posteriormente, estos esfuerzos fueron cooptados por el Estado, proceso también evidente en el campo de la educación como lo expresa una de las líderes en la creación de escuelas: "Yo recuerdo que nosotros nos reuníamos en una de las casas para darles la clase a los niños. Eran casas muy sencillas; luego más adelante llegaron los señores del Gobierno cuando ya teníamos casi todo listo y allí se construyó una de las escuelas públicas. [...]. A mí me dejaron por fuera y así se fueron haciendo los colegios en el sector"

Las instituciones de cobertura educativa nacen como "escuelas de garaje" -denominación con que popularmente se les conocía- en casas de familia, donde inicialmente se cuidaban a los hijos de vecinos, parientes y amigos, para transformarse poco a poco en colegios formales. Hoy persisten algunas instituciones a medio construir que funcionan en pequeñas casas, sin áreas adecuadas para el descanso y la recreación y con salones estrechos saturados de estudiantes. Desde sus inicios-según palabras de los mismos pobladores- estas instituciones cumplían la función social de cuidar a los menores lo cual generaba confianza en las personas del barrio, quienes veían en ellas una opción a la educación oficial. Sin embargo, su excesiva propagación, las evidentes precariedades en su estructura y las condiciones laborales indignas han redundado en una tremenda falta de "calidad educativa". Como refiere un diario local "[...] en Aguablanca es más fácil montar un colegio que abrir una tienda. Usted consigue una casa, diez pupitres, un letrero, inscribe el colegio en el núcleo y con eso lo abre. Pero una tienda necesita estantería y surtido que vale plata" (El País, 2006).

Tal proliferación conlleva el riesgo de convertir a las instituciones -derivadas de las mismas necesidades- en entes cuyo objetivo es generar ganancia, dado que el Estado les paga por cada estudiante atendido. Es así como fenómenos como los "estudiantes fantasma" y las nóminas paralelas, entre otros problemas ${ }^{10}$, terminan por afectar la buena formación educativa.

Según un reporte de la Secretaría de Educación Municipal las matrículas educativas en las comunas 13 y 14 del Distrito de Aguablanca para el periodo 2007-2008, la población en edad escolar era de 78.789 estudiantes, de los cuales el $31 \%$ se matriculó en instituciones educativas oficiales, el $44 \%$ en el sistema subsidiado o de contratación (cobertura), el 19\% escoge en instituciones priva-

7. El 12 de diciembre de 1979 un terremoto de 7,9 en escala de Richter provocó un tsunami que afectó fuertemente la ciudad de Tumaco en la costa pacífica colombiana y sus alrededores, lo cual significó el desplazamiento masivo de muchos de sus sobrevivientes quienes en ese entonces se ubicaron en los predios de lo que se denominaba (entre otras haciendas) el Hato Camagüey, hoy parte del DAB (El País, 2012).

8. Palabras de una docente, quien lleva veinte años en el Distrito de Aguablanca y participó del Diplomado Memoria, educación y desplazamiento" llevado a cabo por el proyecto de investigación y sus entidades vinculadas (2013).

9. Se denomina a aquella población registrada en el sistema educativo como "matriculada" que en la realidad no aparece.

10. Palabras de una docente, quien lleva veinte años en el Distrito de Aguablanca y participó del Diplomado Memoria, educación y desplazamiento" llevado a cabo por el proyecto de investigación y sus entidades vinculadas (2013). 
das y el $6 \%$ está por fuera del sistema educativo formal.

Aunque se tenía previsto desmontar paulatinamente este sistema de contratación educativa, ello no fue posible (como se planteó en el Plan de Desarrollo) dado que el $79 \%$ de esta matrícula se concentra en cinco Comunas del oriente de la ciudad $(6,13,14,15$ y 21$)$ donde se ubica el mayor déficit de cupos educativos, pues la infraestructura educativa oficial no creció pero sí lo hizo la población escolar.

Ahora bien, en los últimos años y sobre la base de estas deficiencias estatales en el campo de la educación, se crearon las denominadas ciudadelas educativas, instituciones que buscan mejorar el sistema educativo en cuanto a la cobertura y la infraestructura urbanística y de paso convertirse en el epicentro de la construcción de un nuevo tejido social de carácter ciudadano. Sin embargo, la construcción y puesta en funcionamiento de dichas instituciones no ha sido un asunto fácil de asimilar por parte de una ciudadanía acostumbrada a los colegios de barrio administrados por sus vecinos. En conversaciones con docentes del sector y ante la pregunta de por qué los habitantes de una de las comunas del DAB preferían matricular sus hijos en otras instituciones y no en las nuevas instalaciones de una de las ciudadelas educativas, referían que "[...] ese lugar donde se construyó el colegio era para hacer un parque y no para llenarlo de cemento; tampoco nos consultaron"11.

Los problemas de cobertura e infraestructura educativa en el Distrito de Aguablanca son apenas la punta del iceberg. El DAB enfrenta, asimismo, múltiples y complejos asuntos que se trasladan al aula:

Cali enfrenta una realidad y es el incremento de las bandas criminales, como los Rastrojos y los Urabeños en la zona urbana. Es un apoderamiento de zonas territoriales pero con un agravante que hemos venido denunciando: la utilización de jóvenes y menores de edad. Este año hemos identificado más de 300 jóvenes que han sido reclutados por estas bandas para el control territorial a través de pandillas o de las llamadas galladas [...]. La personería determinó que en Cali hay más de 135 pandillas [...]; hemos trasladado un conflicto de la zona rural a nuestras zonas urbanas ${ }^{12}$.

Dinámicas del conflicto sociopolítico sin frontera engloban lo rural y lo urbano de distintas maneras y a través de múltiples modalidades, pero con los mismos efectos: incremento de los homicidios, violencia, microtráfico y reclutamiento de jóvenes, quienes ante la ausencia de otras posibilidades caen en las mismas trampas. "La primera causa de mortalidad en este sector es la violencia y son los jóvenes las primeras víctimas (y también victimarios) del conflicto de la zona" (Grupo Investigación y Democracia, 2007. Observatorio social de la Alcaldía de Cali, en P.E.I de Ciudadela Educativa Nuevo Latir, 2011).

En este panorama de tensiones, dificultades y búsquedas se sitúan las personas en situación de desplazamiento quienes a su vez traen las suyas, las cuales se suman a estas dinámicas y complejizan aún más las circunstancias. ¿Cómo es, entonces, su llegada?

\section{El sistema educativo y la situación del desplazamiento forzado}

¿Dónde matricular a los niños? ¿Me recibirán sin papeles? ¿Habrá cupo? ¿Con qué ropa lo mando a estudiar? ¿Con cuáles zapatos? ¿A quién preguntarle?, son las preguntas con las que se enfrenta una familia al llegar a la ciudad en condición de desplazamiento. Al mismo tiempo, ¿qué implica para una persona recién llegada a la ciudad sin documento de identidad alguno obtener un registro civil, certificado fundamental para cualquier proceso administrativo?

Es comprensible, entonces, -aunque no para todos los casos- esperar tras una situación de desplazamiento forzado que gran parte de las personas huyan, como ellos mismos lo refieren, "con lo que tenían puesto" sin tiempo para diligenciar certificados. Más aún, muchas personas luego de su arribo afirman no haber gestionado documento alguno (certificaciones, registros civiles, documentos de identidad, entre otros, esenciales en la ciudad). "Allá nos conocíamos con todos", afirman, y por

11. Conversaciones con docentes del DAB en el marco del Diplomado del proyecto (marzo-agosto de 2013).

12. Entrevista de la W radio al Personero Municipal de Cali Andrés Santamaría. 
tal motivo los documentos no eran necesarios. Ello hizo que algunas instituciones educativas recibieran a los estudiantes en condición de desplazamiento sin la documentación solicitada con la condición de presentarla después.

Gestionar un documento como el registro civil no tiene para ellos la misma dimensión que tiene para los habitantes de la ciudad. Es un asunto de menor importancia; sin embargo, en ocasiones se convierte en un primer obstáculo para el ingreso al sistema educativo, lo cual denota otras formas de interacción con su entorno no visibles a la luz de la "urbanidad"13:

Hay nińos que llegan al colegio con la documentación incompleta. Analizamos que puede ser por dos causas fundamentales: para ellos no es necesario a veces la documentación. Por el lugar donde viven no hay exigencias ni del Estado ni de las instituciones. Otra causa es por temor; entonces, se rehúsan a dar la papelería o tener documentación, pues se encuentran en situaciones de peligro y temen que al exigirles papeles se les esté haciendo alguna investigación y corra peligro la vida de ellos y de su propia familia ${ }^{14}$.

Una vez se ingresa al sistema sin la documentación requerida con la condición de entregarla después viene el proceso de asignación del cupo, trámite nada claro a nivel interinstitucional sino más bien difuso. La Alcaldía de de Cali en un comunicado referente al tema ${ }^{15}$, ilustró a los rectores de las instituciones educativas acerca de lo que la Secretaría de Educación denomina Ruta de atención educativa para población víctima del conflicto. Este documento -que ha sufrido múltiples revisiones- da cuenta de varios asuntos dentro de los cuales se destaca que en realidad no se trata de una ruta de atención sino de ingreso al sistema escolar y enfocada específicamente a las instituciones educativas, con el fin de orientarlas acerca de cómo deben proceder cuando acuden personas en condición de desplazamiento a solicitar un cupo.

Esta información, en primer lugar, tiene la dificultad de no ser de amplio conocimiento y divulgación. De hecho, algunos funcionarios que prestan servicios a la población desplazada ${ }^{16}$ reconocen un panorama laberíntico que dificulta cualquier camino. Es así como una familia en condición de desplazamiento que se acerca a la institución educativa más cercana sin distinguir si trata de una institución oficial o de cobertura, debe recorrer un tortuoso camino para conseguir un cupo.

En segundo lugar, por su misma condición de desplazamiento forzado las personas deben vincularse al sistema de atención para población víctima y registrarse mediante una caracterización, tras de lo cual reciben la verificación de haber sido incluidas como víctimas del conflicto armado. En una de las instituciones ${ }^{17}$ se evidencia una situación particular frente a dicha caracterización: aunque gran número de personas afirman ser desplazadas no se han registrado como población víctima. Así, mientras en un curso aparecían solo tres estudiantes registrados como población desplazada, había veinte en tal condición pero no se habían registrado ante la Unidad de Víctimas, razón por la cual no figuraban en el Simat ${ }^{18}$.

¿Por qué no se registran? ${ }^{19}$

Los niños al colegio llegan desorientados. Hay un choque de valores y de costumbres. Las necesidades básicas no son resueltas. Son muchas complicaciones, ¿̇cierto? Los niños llegan con unas costumbres y unos valores autóctonos y cuando llegan a la ciudad esta les dańa todo ese pensamiento, todos esos valores. Cuando el niño llega a la ciudad tiene que crear una coraza para poder protegerse del medio y

13. Categoría en comillas de acuerdo con las distintas discusiones (Kay, 2007; Galindo y Delgado, 2006; Arias, 2006 ) acerca de las nuevas identidades interurbanas o ruralidades urbanas ("rurbano") permeadas por la modernidad.

14. Palabras de un docente del Distrito de Aguablanca. Mesa de trabajo llevada a cabo en la Universidad de San Buenaventura Cali, 2012. Archivo de audio.

15. Alcaldía de Santiago de Cali. Secretaría de Educación. Circular 2013414320000121 del 18-02-2013.

16. Se ha dialogado con entidades como la Secretaría de Educación, Ciudadela Educativa Nuevo Latir y Unidad de Atención a Víctimas en el Distrito de Aguablanca acerca de la ruta de atención a población desplazada, entre otros aspectos. (2013, actas de reunión)

17. Ciudadela Educativa Nuevo Latir, la cual lleva dos años de haber inaugurado su sede en el sector de Mojica en la Comuna 14 del Distrito de Aguablanca. En marzo de 2013 contaba con cerca de noventa y ocho familias caracterizadas en condición de desplazamiento.

18. El Simat es el sistema integrado de matrículas, una herramienta para organizar y controlar el proceso de matrículas en todas sus etapas.

19. Cuando una persona llega en condición de desplazamiento tras ser expulsada de su territorio, debe acercarse a la Unidad de Atención Integral a las Víctimas para ser reconocida como tal y acceder a los programas de atención. 
esa coraza es la que lo hace estar a la ofensiva y a la defensiva para poder sobrevivir ${ }^{20}$.

"Yo llegué amenazado. No quiero que me identifiquen $[\ldots]$ ".

El miedo, según una docente a cargo del programa Brújula ${ }^{21}$ y el rector de la institución que lo acoge, es uno de los motivos para no registrarse. Miedo a las situaciones de violencia de las cuales huyeron; miedo a ser identificados, reconocidos; miedo a la misma relación con la ciudad; miedo a todos los cambios abruptos ante los cuales deben establecer rápidamente nuevas coordenadas dentro de las cuales les es difícil transitar. "En la mayoría de los casos se encuentra que la población no quiere ser reconocida como desplazada, bien sea para evitar la persecución de grupos al margen de la ley o para que sus hijos no sean estigmatizados en los colegios" (Castillo, 2007, p. 32).

En Cali, la cobertura educativa para la población desplazada es aún más preocupante. Según un informe efectuado para la Secretaría de Educación de la Alcaldía de Santiago de Cali (Ríos, 2009), de acuerdo con el número de la población desplazada registrada y atendida en el año 2009 en el Simat y los datos de registro del año 2008, de 2.183 estudiantes solo se estaría atendiendo aproximadamente el 11,11\% de los niños en edad escolar (5-17 ańos). De ese porcentaje, el $91 \%$ se instruye en la educación tradicional (oficial o de cobertura), seguido del $4 \%$ que se inscribe en modelos de educación para adultos y el $5 \%$ restante se educa en los modelos de círculos, aceleración, escuela nueva, posprimaria y telesecundaria ${ }^{22}$.

Es decir, un alto porcentaje de la población en edad escolar en condición de desplazamiento no está inmersa en el sistema educativo y ello sin considerar los que están por fuera del registro oficial de la UAIV ${ }^{23}$. La situación se torna más compleja dado que tampoco es claro cuántos desplazados hay en Aguablanca. Para la alcaldía estos ascienden a 75.000, pero estudios de otras entidades superan ampliamente esta cifra. Incluso, en la actualidad continúan llegando desplazados de gran parte del suroccidente del país y de otras zonas de la ciudad.

¿Qué representan para ellos la certificación de población víctima y el trámite de la documentación? ¿Cómo acompañar la sensibilización frente a estos procesos que tienen distintos sentidos según quien los enuncia y quien los recibe? ¿Qué implica todo esto en el aula?

\section{Dentro del sistema, en el aula}

Como se refirió anteriormente, la ruta de atención educativa propuesta hasta la fecha llega hasta la asignación del cupo. Sin embargo, a nivel nacional el Ministerio de Educación Nacional promulgó la normatividad que la contempla desde $1997^{24}$ -con algunos antecedentes de otros gobiernos-y no la ha actualizado hasta el día de hoy. De este cuerpo legislativo se destaca lo siguiente:

El Ministerio de Educación Nacional y las secretarías de educación departamentales, municipales y distritales, adoptarán programas educativos especiales para las víctimas del desplazamiento por la violencia. Tales programas podrán ser de educación básica y media especializada y se desarrollarán en tiempos menores y diferentes a los convencionales, para garantizar su rápido efecto en la rehabilitación y articulación social, laboral y productiva de las víctimas

20. Palabras de un docente del Distrito. Mesa de trabajo, Universidad de San Buenaventura Cali, 2012. Archivo de audio.

21. Programa dirigido a niños, nińas y jóvenes en condición de extra edad que por diferentes razones no han aprendido a leer y escribir.

22. El mismo informe plantea dentro de sus recomendaciones la necesidad de generar estrategias educativas flexibles para atender pertinentemente a la población vulnerable que demanda la atención de un servicio educativo especial.

23. Al respecto, la alcaldía municipal en su Plan de Acción Territorial para Atención a Víctimas del Conflicto, se compromete al mejoramiento de los procesos de atención educativa a la población escolar víctima del conflicto armado, matriculados en instituciones educativas oficiales y de cobertura y su meta es pasar de atender 2893 estudiantes en el 2011 (como línea de base) a 5000 en el periodo 2012-2015.

24. En 1997 se inicia, con algunos antecedentes previos, un programa de atención a la población escolar desplazada el cual incluyó capacitación de docentes y dotación de textos (MEN, 2001). Posteriormente, el MEN y la Corporación para el Desarrollo Humano (Humanizar) adelantaron una investigación con desplazados en Bocas del Atrato (Turbo, Antioquia) y con docentes de Carmen de Bolívar, para diseñar una propuesta de formación de maestros que trabajaran con este tipo de población, lo cual derivó en la propuesta Escuela y desplazamiento (MEN, 2007). Esta contiene, entre otros asuntos, algunos aspectos del marco ético y legal de las personas en condición de desplazamiento, particularidades psicosociales y algunas herramientas pedagógicas para los maestros. En cuanto a lo local, ha habido también iniciativas de la alcaldía municipal en convenio con la Universidad del Valle en la formación docente a través de un Diplomado para la atención a población infantil en condición de desplazamiento (2011-2013), entre otras experiencias. 
del desplazamiento interno por la violencia (Ley 387 de 1997. Sección 8 artículo 19 numeral 10).

Dichas iniciativas tienen por objeto la formación de docentes que atienden a la población en condición de desplazamiento; orientar la capacitación y formación de adultos, quienes en esta situación suelen presentar altos índices de analfabetismo; incentivar a los entes locales para conseguir recursos para tales fines; diseñar metodologías que apoyen la atención a las necesidades educativas de la población desplazada; y, por último, contribuir al fortalecimiento de los programas Aceleración del Aprendizaje, Telesecundaria, Servicio de Aprendizaje Tutorial, Escuela Nueva y Cafam, entre los más destacados. No obstante, ante los altos índices de menores en condición de desplazamiento, tales iniciativas no cuentan con la cobertura necesaria para cubrir las diferentes regiones del país ${ }^{25}$. En este sentido, una educadora de la Comuna 14 de Cali plantea lo siguiente:

En las instituciones educativas existen los programas

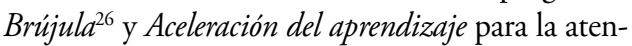
ción de la población en condición de extra edad que no supiera leer y escribir. Estos programas no fueron diseñados para personas en condición de desplazamiento; sin embargo, son los que mayor número de desplazados reciben. En mi institución estos programas requieren adaptación, los contenidos están orientados solo a lectoescritura y los materiales son muy distantes de los niños que nos llegan. ${ }^{27}$

$\mathrm{Al}$ respecto, otro educador de la Comuna 21 afirma: "En la institución [...] no se da un trato especial a las personas en condición de desplazamiento. Ellas llegan con el papel de la UAO, ingresan, pero no existen esos programas de aceleración del aprendizaje ni nada por el estilo".

Un docente, participante de las mesas de trabajo, plantea lo siguiente: "Algunas iniciativas del Ministerio de Educación y la Secretaría de Educación de Cali para atender el problema del desplazamiento a veces se hacen desde lo macro, pero no se contextualizan a las situaciones reales de los contextos comunitarios donde están las instituciones. Entonces existen propuestas pero no atienden a la diversidad y a la diferencia" ${ }^{28}$.

¿Es un asunto de voluntades? ¿Hasta dónde algunas instituciones implementan estos programas o por el contrario, se hacen los de la vista gorda? ¿Qué va pasa, entonces, con aquellas delicadas raíces que aun lastimadas están en la búsqueda de anidar nuevamente en un espacio que les permita arraigarse?

Una habitante del barrio Marroquín II $^{29}$ afirmaba haberse visto obligada a retirar a su nieto de la escuela "[...] porque en el salón le decían $e l$ desplazado".

¿Qué esfuerzos adicionales requieren las personas en tal situación para volverse a enraizar?

Se evidencia, entonces, que la marginalidad social de las personas en condición de desplazamiento se traslada al aula. La condición de "ser otro", la condición de alteridad, produce incomodidad en el entorno. Ese otro llega con sus quejas y demandas diferentes, con un lenguaje propio; ese otro, visto a los ojos de sus compañeros, es el "raro", el "llorón", el "bravo", el "solitario", el "callado", "el viejo" (extra edad); una serie de adjetivos (a modo de juicio) que fomentan distancias en apariencia insalvables. En este sentido, Skliar (2002) nos pone en evidencia: en el otro, en el diferente se reconoce y devela la "incomodidad" de la otredad: "El otro solo es otro en la medida en que pueda ser capaz de mostrarme -claro, siempre a una distancia prudencial- [...] quiénes somos nosotros y cuáles ajustes debemos hacer para parecernos cada vez más, a nosotros mismos" (Skliar, 2002, p.14).

Parecernos a nosotros mismos es esperar que ese otro siga los mismos códigos, reglas, lenguajes y gestos del colectivo. En esa dimensión, la escuela para las personas en condición de desplazamiento se convierte en otro territorio de expulsiones. Nuevamente, se hace presente la sensación del

25. Existen también otras valiosas iniciativas de la sociedad civil como es el caso de la Corporación Opción Legal, la cual viene desarrollando a partir del ańo 2001 y en diferentes regiones del país el proyecto "Pedagogía y protección de la niñez" que trabaja específicamente con los infantes desplazados y docentes de la comunidad receptora.

26. Ver más acerca de los programas en: http://www.fundacioncarvajal.org.co/sitio/index.php?option=com_k2\&view=item\&id=72: aceleraci\%C3\%B3n-del-aprendizaje\&Itemid=12\&lang=es.

27. Palabras de una docente de DAB participante del Diplomado del proyecto (2013).

28. Representante de ONG Paz y bien, participante de mesa de trabajo, 2012. Archivo de audio.

29. Mujer en condición de desplazamiento del programa Jueves de paz de la Fundación Paz y bien, quien llevaba a su nieto a una de las escuelas de la Comuna 14. Conversaciones informales, 2012. 
desarraigo y el marchitamiento de la vida ocasionados por un entorno donde se le hace ver y sentirse distinto. Se hace más honda la herida, lo cual llama a la comunidad receptora a proveer y proveerse de comprensiones y movilizaciones; a batallar contra la propia tendencia a la exclusión; retos de dimensiones hondas no solo para el aula en este caso, sino para la sociedad en general.

\section{“No conviene recibir población desplazada"}

Las zonas fronterizas en Cali como el DAB, son sectores con graves problemáticas sociales donde los índices de violencia y conflictividad denotan necesidades y carencias sistemáticas ${ }^{30}$. El científico social Santiago Arboleda (2008), basado en las perspectivas poscoloniales y en relación con las ciudades latinoamericanas, emplea los términos de "centro" y "periferia" para referirse a este problema. La periferia advierte esos espacios de exclusión y marginalidad representada en este caso por el DAB. Tal estigma conlleva en sí mismo juicios cargados de incomprensión histórica sobre lo que ha implicado "levantar" el Distrito para sus habitantes. Aunque persisten múltiples carencias, emergen más y más tejidos solidarios que pugnan de manera creativa entre la dificultad y las resistencias.

Este contexto recibe constantemente oleadas de personas desplazadas que buscan asentarse y se encuentran con múltiples resistencias. En el ámbito escolar, se patentizan situaciones como la siguiente: "A las instituciones educativas realmente no les conviene recibir población desplazada porque les baja el puntaje en las pruebas del Icfes [...]"31.

Esta problemática afecta fuertemente a la población en condición de desplazamiento, cuyos miembros además de ingresar a sistemas educativos de baja calidad (situación más grave en los colegios de cobertura) se convierten en la "papa caliente" de las instituciones educativas que ven en ellos un "problema" administrativo y burocrático de difícil atención. Lo anterior no implica desconocer el esfuerzo del sistema al movilizarse, crear políticas y propiciar estrategias que ayuden a superar dichos obstáculos. Por cierto, en ocasiones la llegada de población desplazada al aula ha hecho de este espacio una fuente de riquezas materializadas en actitudes de sensibilización con la otredad y de reconocimiento a la diversidad y a la pluralidad cultural, en un país heterogéneo y pleno de historias.

¿Hasta dónde la escuela debe cubrir las carencias de la estructura misma? ¿Qué le corresponde atender? ¿Qué hacer con los problemas sociales afrontados día a día en el aula? Los maestros constantemente se cuestionan y le preguntan a la sociedad cómo atender a una población con tanta vulneración; cómo identificar situaciones mayores de orden clínico sin contar con el apoyo psicosocial requerido en el aula; cómo trabajar con todo esto y a su vez "cumplir" con contenidos, evaluaciones e informes.

Uno hace y hace y hace y realmente queda en nada; no hay un seguimiento. No se puede hacer un seguimiento porque tú llegas, coges un muchacho, lo identificas y determinas que tiene problemas de aprendizaje o llegó del campo y por su contexto social hay que hacer un trabajo con ese joven para vincularlo a la comunidad, a la institución y que no haya rechazo de parte de la comunidad. Entonces, hacemos ese trabajo, llegan hasta allí y requerimos de una colaboración de otros entes, de otras disciplinas; del psicólogo, la terapista ocupacional, la fonoaudióloga, un médico...

Uno hace todo ese análisis y no hay el psicólogo o terapista. Entonces, es como crear una estrategia desde el Gobierno, la Secretaría de Educación, de cada uno de los entes que estamos aquí reunidos; mirar cómo creamos esa estrategia de tal forma que eso no quede ahí y haya un seguimiento, un acompañamiento para sostener esos jóvenes que llegan a las instituciones con una permanencia siquiera del año académico. Porque nos llegan en enero y se van en febrero o en marzo; regresan el siguiente año en enero y se vuelven a ir en junio. Entonces,

30. El ingeniero civil Claudio Borrero Quijano ha insistido acerca del riesgo de colapso sanitario que vive el DAB al entregarle al colector Cauca todas las aguas residuales del corredor Cali-Jamundí, cuya área expansiva de 1.658 hectáreas no tiene protección de jarillones defensivos contra la inundabilidad cotidiana por desbordamientos del río Cauca. Además, al estar por fuera del perímetro sanitario no dispone de los servicios públicos esenciales para garantizar un urbanismo idóneo. Ver: http://caliescribe. com/estudios-urbano-regionales/2013/03/02/4031-porque-aguablanca-quedara-alto-riesgo-colapsar-sanitariam.

31. Palabras de un administrativo perteneciente a una institución educativa del Distrito en entrevista informal con la investigadora. 
no tenemos esa continuidad del proceso educativo del muchacho desplazado ${ }^{32}$.

Así, entre idas y venidas, entre trámites y documentos, entre miradas y voces que nunca logran visibilizarse en el aula; entre los barrios que se no pueden comunicar unos con otros por las llamadas "fronteras invisibles" 33 se descubren talentos culturales potentes como los generados en torno a la música y redes sociales que se organizan para intentar armonizar este complejo paisaje de tensiones. De esta forma se gestan los procesos educativos de las personas en condición de desplazamiento, quienes van buscando un nicho de refugio y de condiciones propicias para un enraizamiento.

\section{Más allá del DAB. Un panorama global}

El Distrito de Aguablanca, como se ha referido, es un espacio único, diverso, complejo y lleno de riquezas, pero también de dificultades. Una atmósfera donde existen muchos jóvenes con sueños truncados, familias disfuncionales y violentas y para nuestro caso sumidos en un sistema escolar excluyente $^{34}$. Aguablanca es un epicentro humano para el aprendizaje y la búsqueda de soluciones más allá de las tradicionales medidas policivas y de intervenciones sociales cortoplacistas. Es un espacio para el rescate de la autogestión y de los procesos incipientes de creación de identidades locales dentro de la diversidad, más aún cuando se ha convertido en un centro de permanente recepción de los desplazados.

Para tener otras ópticas en la comprensión de este micro/macro escenario en relación con la educación y el desplazamiento, es oportuno discernir cómo son abordadas estas categorías en el panorama mundial.

¿Qué hay en el contexto mundial que ayude a desentrañar estas tensiones del marco local? Las migraciones y los desplazamientos ${ }^{35}$ por conflictos políticos, sociales, culturales, étnicos y religiosos se han dado en diversas latitudes y épocas de la historia humana ${ }^{36}$; es decir, es un problema antiquísimo con denominadores comunes: la lucha por el dominio territorial y por el control del poder político, económico, étnico, religioso o cultural, pero ello no significa naturalizar el hecho ${ }^{37}$. Hay autores que plantean estas discusiones como paradigmas de la cultura patriarcal; sin embargo, otorgarle una dimensión histórica en este texto tiene por objeto hacer evidente el problema como un asunto que va más allá de lo que alcanzamos a observar.

La Unesco (2011) concibe su efecto en la educación como uno de los aspectos más perjudiciales y al mismo tiempo menos conocido en los países afectados por conflictos y ello se refleja en los peores indicadores del mundo.

¿Cómo se relaciona este problema mundial con lo descrito en Aguablanca? Al inicio de este escrito se aludía a la educación en relación con el desplazamiento como un aspecto de "segundo orden", en cuanto hay necesidades de supervivencia que priman sobre esta. Pero, ¿`ómo nos perjudica el impacto educación/desplazamiento? ¿Por qué es el menos estudiado y se le dedican menos recursos y esfuerzos institucionales?

La crisis encubierta de la educación en los Estados afectados por conflictos constituye un problema mundial que exige una respuesta de la comunidad internacional. Además de socavar las perspectivas de impulsar el desarrollo económico, de reducir la pobreza y de alcanzar las metas fijadas en los Objetivos

32. Palabras del coordinador académico de una institución educativa del Distrito. (Mesa de trabajo, Universidad de San Buenaventura Cali. Archivo de audio).

33. Al respecto ver http://www.semana.com/nacion/articulo/el-desafio-del-distrito-aguablanca/345780-3; http://www.elpais.com.co/ elpais/judicial/noticias/estas-son-fronteras-invisibles-marcan-pandillas-para-defender-sus-territorios; entre otras fuentes.

34. El sector educativo (oficial y privado) de Cali no cuenta con la oferta suficiente para garantizar la continuidad de los estudiantes que terminan la básica secundaria (Ríos, 2009).

35. Para Uganda y Ruanda el desplazamiento está asociado a la doble condición de refugiado y desplazado. Allí se dan condiciones particulares de migraciones y éxodos masivos a causa del conflicto, a diferencia de Colombia donde el desplazamiento "gota a gota" tiende a aumentar. Como ya se ha mencionado, en Haití el desplazamiento está asociado a los desastres naturales y en India al desarrollo (Segunda reunión anual del proyecto intercontinental Prevención de riesgos asociados a los desplazamientos de población. Definir modelos de acción educativa, llevada a cabo en las instalaciones de la Universidad Católica de Colombia, Bogotá, los días 26-28 de junio de 2013).

36. En la Biblia, por ejemplo, en el pasaje del Éxodo (segundo libro del Antiguo Testamento) se hace referencia a la salida de los esclavos de Egipto camino al pueblo de Israel, cuyos orígenes se remontan al ańo 1447 a. C.

37. Se recomienda revisar al respecto El cáliz y la espada, de Riane Eisler, Editorial Cuatro Vientos. 
de Desarrollo del Milenio, los conflictos armados están aumentando las desigualdades, la desesperanza y el sentimiento de injusticia que encierran a los países en el círculo vicioso de la violencia (Unesco, 2011, p. 2).

La Unesco hace aquí varias advertencias que en nuestro caso también se ponen en juego. El conflicto armado, además de segregar, aumenta los cordones de pobreza de las ciudades -como sucede en Aguablanca- y genera desesperanza en la población infantil y juvenil. La misma entidad reconoce en la educación un poderoso factor de paz; sin embargo, actualmente la escuela cae en la instrumentalización a consecuencia del excesivo peso que le significa centrar la evaluación en la falsa idea de medir la calidad educativa con la mira puesta en el mundo de trabajo, descuidando de esta manera los procesos de formación ciudadana y humanista y reforzando, a su vez, las divisiones sociales y de exclusión.

Hay señalamientos en el panorama internacional presentes asimismo en nuestro territorio, entre los que se destaca el bajo presupuesto de las naciones en conflicto en el campo de la educación (Collier, 2008, 2009; Hoyas y Puerto D, A., 2011; Unesco, 2010, 2011; Coalico, 2007; Banco Mundial, 2011; Oxfam, 2012). Gran parte del apoyo para la educación en dichos países proviene de entidades internacionales; sin embargo, con la crisis financiera mundial estas ayudas se han visto reducidas y cuando se orientan a la educación se enfocan a la educación superior. De hecho, en nuestro país además de la reducción de ayudas y los bajos presupuestos asignados para la educación, el gasto militar supera en mucho al de la inversión en educación, lo cual contradice las altas expectativas depositadas en esta última. Por ejemplo, en estos momentos de diálogo para superar el conflicto al hacer un balance del programa de Gobierno, es evidente que la educación no es una prioridad. Las llamadas locomotoras minera, agroexportadora, de infraestructura y de inversión extranjera no la tienen en cuenta. Una situación también evidente a nivel global, como lo afirma la Unesco:

En muchos países afectados por conflictos, el gasto dedicado a las operaciones de seguridad y la ayuda humanitaria predomina en la ayuda dispensada por los donantes, mientras que el gasto para el desarrollo a largo plazo en general y para la educación en particular, queda relegado a un segundo término.
Se estima que en 2008 la educación representó solamente el $2 \%$ de la ayuda humanitaria total, esto es, 237 millones de dólares (Unesco, 2010).

Más ayuda para la guerra y no para la paz. Llegados a este punto, vale la pena preguntarse en qué suelos hunden las raíces que en el presente texto se han establecido metafóricamente. Cuáles son sus condiciones de "aridez" o de potencialidad (en términos de recursos, posibilidades, inversión), de sequía o de "humedad para construir escenarios de paz".

En el panorama mundial, juega un papel fundamental el crecimiento de la población juvenil e infantil y la categoría de género. Gran parte de los jóvenes desplazados por el conflicto son niñas y en el caso colombiano un alto porcentaje son indígenas y afrodescendientes. Las mujeres y las niñas víctimas de conflicto tienen, entre otros asuntos, menores posibilidades de ingreso a los sistemas escolares por situaciones de embarazo, exclusión del sistema mismo y hacerse cargo de la familia. "Las mujeres y las niñas suponen el $48 \%$ de los refugiados y la mitad de los desplazados internos y retornados (antiguos refugiados)" (Acnur, 2011).

En el DAB, la mayoría de adultos desplazados son mujeres; sin embargo, en cuanto al número de niños y niñas no es tan sencillo hacer esta caracterización por las razones mencionadas al inicio acerca de los temores u otras motivaciones para no hacerse visible como desplazado. Esto implica para las acciones planeadas considerar en las propuestas la categoría género y distinguir entre niños, niñas, hombres y mujeres.

¿Qué expectativas de proyectos de vida, de construcción de futuro tienen las personas víctimas de conflicto? ¿Qué podríamos decirles a los jóvenes, a los niños y niñas frente a estas situaciones? En Colombia en correspondencia con el panorama mundial, se calcula del total de la población en situación de desplazamiento, cerca de 1.100.000 niños y niñas están en edad escolar (Codhes, citado en Lerma C., 2007).

Las entidades estatales encargadas de liderar los procesos educativos, coinciden en afirmar que se deben implementar políticas de integración escolar para la población marginada del sistema educativo bien sea por condiciones de extra edad, diferencias culturales, mayor necesidad de inclusión de 
políticas de género e interculturalidad, entre otros (MEN, 2001).

Al presentar menores niveles de escolaridad, menores tasas de asistencia educativa y niveles de analfabetismo mayores, los desplazados se encuentran en una posición precaria, incluso frente a los pobres urbanos, que se manifiesta de manera diferente para los distintos grupos poblacionales (Ibáńez y Moya, 2007, p.13).

Estas inequidades que no aparecen de modo explícito y frente a las cuales no se tienen respuestas claras, generan tensiones y contradicciones que hay que tener en cuenta a la hora de considerar a la población desplazada en las aulas. Sin embargo, acercarse al fenómeno con una visión crítica significa construir posturas diferentes y propositivas y entender que tales tensiones son un desafío para todos aquellos inmersos en la educación, en este caso y por supuesto para el Estado y la sociedad en general.

¿Cómo logran, entonces, las personas en situación de desplazamiento en el contexto educativo sortear las tensiones? ¿Qué facilita o propicia a las raíces encontrar poco a poco asidero?

Las raíces como tales, pueden ser sometidas a cambios estructurales en la mayoría de los casos relacionados con adaptaciones al medio ambiente, gracias a lo cual surgen las denominadas raíces reservantes que de alguna manera serían las contenedoras de vestigios de memoria de la identidad de la planta, para que pueda revivir en nuevos escenarios.

\section{Conclusiones}

En primer lugar, sería obtuso no reconocer -como lo plantearon los participantes del proceso de investigación y construcción colectiva de preguntas y respuestas- la variedad de desplazamientos y sus oleadas, aunque la investigación se circunscribe al marco del desplazamiento forzado desde el punto de vista de la normatividad colom- biana ${ }^{38}$. Un desplazamiento que afecta de múltiples maneras, tanto a la comunidad del Distrito como a la ciudad de Cali y por supuesto a quienes arriban tras la huida de situaciones derivadas del conflicto armado:

Partimos de aclarar que estamos hablando de un desplazamiento en términos generales, no solamente del desplazamiento forzado reconocido por la institucionalidad colombiana y desde ese punto de vista nos damos cuenta de que en las comunidades donde nosotros trabajamos a los estudiantes los afectan diversas formas de desplazamiento. Unas son desplazamientos entre comunas donde salen y llegan personas; otras entre barrios y sectores de barrios; $y$ otro interaulas, incluso al interior de las instituciones educativas, las cuales se deben generalmente a situaciones de conflicto con manifestaciones de violencia donde no necesariamente se ven involucradas bandas muy fuertes sino la micro extorsión ${ }^{39}$.

Derivado de lo anterior, se plantea un debate que aunque en términos legales no se quiere asumir como tal, tiene repercusiones en el ejercicio práctico. Es el caso de los desplazamientos entre comunas y barrios generados por las Bacrim. "[...] se desató una polémica porque los ponentes de la ley y el Gobierno acordaron que las víctimas que se podrán beneficiar son las del 'conflicto armado'. Esa expresión no había aparecido en las discusiones. El objetivo de la inclusión es delimitar el universo de víctimas para que queden por fuera las de la delincuencia común" (Paredes C., 2011, p.65). Esta discusión debe darse y en relación con el desplazamiento forzado se han dado situaciones de "doble desplazamiento" tanto por el conflicto armado como por las dinámicas replicadas en la ciudad. ¿Cómo no tener en cuenta estos eventos? ¿Qué genera para las personas esa "doble" y en ocasiones "triple" movilización forzada? ¿Cómo afecta al ejercicio de enraizamiento, a la capacidad de sostenerse, a las instituciones y a la vida misma?

Por otro lado, hay buenas expectativas en el sistema educativo en relación con la atención a la población en condición de desplazamiento; sin embargo, los docentes mismos reconocen por una

38. "Es desplazada toda persona que se ha visto forzada a migrar dentro del territorio nacional abandonando su localidad de residencia o actividades económicas habituales, porque su vida, su integridad física, su seguridad o libertad personales han sido vulneradas o se encuentran directamente amenazadas, con ocasión de cualquiera de las siguientes situaciones: conflicto armado interno, disturbios y tensiones interiores, violencia generalizada, violaciones masivas de los derechos humanos, infracciones al derecho internacional humanitario $\mathrm{u}$ otras circunstancias emanadas de las situaciones anteriores que puedan alterar o alteren drásticamente el orden público". Artículo $1^{\circ}$ de la ley 387 de 1997.

39. Participante de ONG, Paz y bien. Mesa de trabajo, 2012. Archivo de audio. 
parte, que muchas de estas perspectivas rebasan las propias posibilidades de comprensión y acción. Los ejercicios mínimos de garantía de derechos son competencia del Estado y en esa tarea se está transitando; empero, para los docentes es vital contar con procesos de acompañamiento, asesoría y opciones de seguimiento u orientación en estos temas a fin de llevar a cabo su labor educativa con población víctima. También refieren la importancia de recuperar su liderazgo como educadores sin restar importancia a los complejos contextos en donde intentan hacer su labor.

Es evidente que abordar las claves educación/ desplazamiento requiere profundizar en un problema con múltiples aristas: sociología del conflicto; aspectos psicosociales y normativos; características del contexto y de la población (la receptora y quienes llegan tras el conflicto); saberes culturales de la población que llega con sus formas de aprendizaje, recursos y organización familiar derivada de la llegada; nociones básicas para comprender los fenómenos de violencia y trabajar en cada contexto. En este sentido, es necesario contextualizar los programas de apoyo reglamentados (Brújula y Aceleración del aprendizaje), superar el énfasis netamente cognitivo e incorporar variables socioculturales que propicien espacios de aprendizaje adecuados para la población en situación de desplazamiento.

Los jóvenes, niños y niñas en condición de desplazamiento presentan un alta vulnerabilidad psicosocial producto de las complejas experiencias y situaciones vividas, las cuales se reflejan en traumas psicológicos y físicos (Acnur e ICBF, 2000). Estas realidades se materializan en el aula a través de comportamientos referidos por los mismos docentes: aislamiento, solipsismo, conductas agresivas, las cuales afectan su situación académica, relacional y de permanencia en el sistema escolar. En esta dirección y según el ejercicio de la metáfora de las raíces reservantes, es claro que se trata de un proceso que no le compete exclusivamente a un sector sino que requiere un trabajo articulado, acercarse a las organizaciones de base que brindan de manera solidaria su respaldo, acompañar al Estado en la formulación de políticas y estrategias y coordinar los programas en la institución. Todo esto forma lentamente tejidos, los cuales desde la perspectiva psicosocial son determinantes en el esfuerzo colectivo de armar sociedad.
Ahora bien, las personas en condición de desplazamiento que llegan a Cali provienen en gran medida del suroccidente del país y en su mayoría son población negra. Traen consigo sus propios lenguajes, sus significaciones, sus construcciones de lo vital, de la familia, de la violencia, de la paz y de la educación. Sin embargo, en tales condiciones intentan habitar nuevos espacios y darles asiento a sus vestigios de raíz, al tiempo que interactúan con el nuevo entorno y buscan ser habitadas por él, por sus dinámicas y por sus lógicas. Algunas lo logran y aunque persiste en muchas un fuerte anhelo del retorno, asumen la voluntad política de los Gobiernos de turno con el deseo de reorganizar poco a poco su existencia. En estas amplias y complejas dimensiones, la educación está en mora de acoger a estos nuevos ciudadanos con memorias de campo, de ruralidad, de culturas, formas de relación y otros saberes en medio de la ciudad, con la necesidad de aprender a habitarla dignamente y del mismo modo ser recibidos por ella.

Por último, es esperanzador encontrar a educadores que trabajan día a día con vocación y procuran, con sus esfuerzos creativos, aportar a construcciones colectivas de paz. Los encuentros con los docentes han referido una y otra vez el valor del vínculo afectivo; la diferencia en el proceso de aprender cuando se recibe al otro con su "otredad" aunque esto cueste; la importancia de trabajar primero con los procesos psicosociales y una vez en curso la posibilidad de introducir lo cognitivo y no inversamente; y el valor de los aprendizajes experienciales que permiten vivir otras situaciones en las cuales se movilicen referentes diferentes a los que traen con respecto a la violencia y reconocer a su vez su propia identidad. Sin embargo, muchas de estas acciones se llevan a cabo en solitario, no tienen voz institucional y se pueden disolver en la premura de la inmediatez del día a día. En esa dirección, la cooperación institucional, el trabajo continuo en sensibilización ciudadana, el fortalecimiento de redes de apoyo, un "cuidar a quienes cuidan", se convierte en un camino por transitar. Horizontes de ruta se abren y transitan pero requieren de constante reformulación ante las cambiantes dinámicas y oleadas de los desplazamientos forzados y del desarraigo que producen. En efecto, son derroteros en los que habrá que insistir ya que ellos son el asidero de lo que se constituye, según este escrito, como las posibilidades de emergencia de la raíz en medio del desarraigo. 


\section{Bibliografía}

- ARBOLEDA, S. (2008). Seminario La colonialidad del saber. Memorias. Facultad de Educación. Maestría en Educación: Desarrollo Humano. Universidad de San Buenaventura Cali.

- CARDONA, S. (2009). Memorias. Maestría en Educación: Desarrollo Humano. Seminario La gesta/gestión del Conocimiento. Universidad de San Buenaventura Cali.

- COLLIER, Paul (2008). El club de la miseria. Qué falla en los países más pobres del mundo. Madrid: Turner publicaciones.

- GONZÁLEZ B., J. D. (2012). Mundos populares entre el desplazamiento y el poblamiento. En: Revista Cientifica Guillermo de Ockham 10(2).

- LIMA, L. (2000). Efectos psicosociales y culturales del desplazamiento. En: Revista de trabajo social 2.

- P.E.I, Ciudadela Educativa Nuevo Latir. 2011. Documento institucional.

- SKLIAR, C. (2002). Alteridades y pedagogías o y si el otro no estuviera ahí. En: Educação y Sociedade, año XXIII, 79. Brasil: Universidade Federal do Rio Grande do Sul.

\section{Webgrafía}

- ACNUR. (2012). Un año de crisis. Tendencias globales 2011. Recuperado desde http://www.acnur.es/PDF/ tendenciasglobales_2011_spa_20120619151451.pdf

- Alcaldía de Santiago de Cali. Asesoría para el Desarrollo, la Seguridad y la Paz Desepaz. Plan Integral Único de atención para población en situación de desplazamiento. (2011-2013). Recuperado desde www.caracterizacion2011psd-valle.pdf

- Arquidiócesis de Cali y Codhes (13 de agosto de 1997). Comisión de Vida, Justicia y Paz. (1996). Estudio exploratorio. Desplazados en Cali: entre el miedo y la pobreza. Recuperado desde http://www.derechos.org/ nizkor/colombia/desplazados/cali.html

- Banco Mundial. (2011). Informe sobre el desarrollo mundial. Panorama general. Conflicto, seguridad y desarrollo. Banco Mundial Washington D.C Recuperado desde http://wdronline.worldbank.org/worldbank/a/ langtrans/67.

- BELLO, M. N. (2003). El desplazamiento forzado en Colombia: acumulación de capital y exclusión social. Conferencia regional "Globalización, migración y derechos humanos". Convocado por la Universidad Andina Simón Bolívar, Quito, Ecuador. Recuperado desde http://www.virtual.unal.edu.co/cursos/humanas/2004945/ docs_curso/descargas/1ra\%20sesion/Basica/Martha\%20Bello.pdf

- Cámara de Comercio de Cali; Fundación Alvar Alice; El País; Casa Editorial El Tiempo, Fundación Corona, Cámara de comercio de Bogotá (2010). Calímetro sobre la contratación educativa en Cali. Recuperado desde http://calicomovamos.org.co/calicomovamos/files/CALIMETRO/Cal\%C3\%ADmetro\%20 Contrataci\%C3\%B3n\%20Educativa\%202010.pdf

- CASTILLO V, A. (2007). ¿Calidad o cobertura? Análisis de la contratación de los servicios educativos en Colombia. Proyecto Educación Compromiso de todos. Impresión Gente Nueva Editorial. Bogotá, Colombia. Recuperado desde http://calicomovamos.org.co/calicomovamos/files/Educacion\%20Compromiso_/Publicaci\%C3\%B3n\%20 Calidad\%20o\%20Cobertura.pdf

- Centro de Memoria Histórica (2013). Basta ya. Colombia: Memorias de guerra y dignidad. Recuperado desde http://www.centrodememoriahistorica.gov.co/micrositios/informeGeneral/

- COLLIER, Paul (2009). Guerra en el club de la miseria. La democracia en lugares peligrosos. En: HOYAS G. M. y PUERTO, D. A. (2011). En Revista Internacional de Éticas Aplicadas ,2(6). pp. 141-157. Recuperado desde http:/www.dilemata.net/revista/index.php/dilemata/article/view/96/100 
- Coalición contra la vinculación de niños, niñas y jóvenes al conflicto armado en Colombia [COALICO] (2007). Informe. Conflicto Armado en Colombia. Fronteras: la infancia en el límite. Recuperado desde http:// www.acnur.org/t3/uploads/pics/2206.pdf?view=1.

- Codhes Informa (2011). Informe sobre desplazamiento, conflicto armado y derechos humanos en Colombia 2010. ¿Consolidación de qué? $N^{\circ} 77$. Recuperado desde http://www.codhes.org/images/stories/pdf/bolet\%C3\%ADn\%2077.pdf

- Corporación Opción Legal (2004). Foros regionales. Con el respaldo de Acnur. Colombia. Recuperado desde http://50.63.158.194/index.php/foros

- El País (2006). Ampliación educativa aún no está libre de males. Entrevista a Franklin Daza, Rector Colegio Comunitario Iván Darío López. Recuperado desde http://historico.elpais.com.co/paisonline/calionline/notas/ Diciembre172006/amplied.html

- GALINDO, C. y DELGADO, J. (2006). Los espacios emergentes de la dinámica rural urbana. Recuperado desde http://www.ejournal.unam.mx/pde/pde147/PDE14708.pdf

- HERNÁNDEZ S. L. (2009). Población desplazada busca nuevas formas de organizarse. Agencia universitaria de periodismo científico (Aupec). Universidad del Valle, Cali. Recuperado desde http://aupec.univalle.edu. co/informes/2009/abril/desplazados.html

- IBÁNEEZ, A. M. y MOYA, A. (2007). La población desplazada en Colombia: examen de sus condiciones socioeconómicas y análisis de las políticas actuales. Departamento Nacional de Planeación. Misión para el diseño de una estrategia para la reducción de la pobreza y la desigualdad. Recuperado desde https://www.dnp.gov.co/ Portals/0/archivos/documentos/DDS/Pobreza/Portadas/POBLACION\%20DESPLAZADA.pdf

- KAY, C. (2007). Estudios rurales en L.A. Institute of Social Studies, La Haya. Recuperado desde http:// es.scribd.com/doc/54407981/Kay-Estudios-Rurales-en-LA-2007

- LERMA C, C.A. (2007). El derecho a la educación en Colombia. Colección libros Flape $6^{\circ}$ Foro Latinoamericano de Políticas Educativas - FLAPE. $1^{\text {a }}$ Ed. Recuperado desde www.foro-latino.org/flape/...Flape/06Colombia_Derecho.pdf

- LEY 387 de 1997 Por la cual se adoptan medidas para la prevención del desplazamiento forzado; la atención, protección, consolidación y esta estabilización socioeconómica de los desplazados internos por la violencia en la República de Colombia. Sección 8 Artículo 19 numeral 10. Recuperado desde http://www. disaster-info.net/desplazados/legislacion/Ley387de1997.pdf

- Ministerio de Educación Nacional [M.E.N] (2001). Publicación en línea. Educación para desplazados: un derecho y un deber. Periódico Al tablero. N. 6. Julio 2001. Recuperado el 12 de enero de 2013 desde http:// www.mineducacion.gov.co/1621/article-87379.html

- _ (2004). Educación para cada situación. En periódico Al tablero 28. Recuperado desde http:// www.mineducacion.gov.co/1621/article-87346.html descargado 12-01-2013

- (2007). Revolución educativa. Plan Sectorial 2006-2010. Documento No8. Recuperado desde http://planipolis.iiep.unesco.org/upload/Colombia/Colombia_plan_sectorial.pdf

- MILLÁN, H. (s.f). La atención humanitaria en el context colombiano. Recuperado desde http://www.corporacionavre.org/files/pdf/LibroNaranja/naranja_2.pdf

- MOLANO, A. (2003). Dialogo con Alfredo Molano. Memorias. En Programa Cátedra Pública — con el apoyo de la Gobernación de Antioquia, el Politécnico Colombiano Jaime Isaza Cadavid y Comfama-Moderadores: María Teresa Uribe, Amparo Murillo y Juan Camilo Ruiz. Recuperado desde http://www.udea. edu.co/portal/page/portal/BibliotecaPortal/ElementosDiseno/Documentos/Rectoria/06-molano-dialogo.pdf

- González B, J.D. (2012). (2001) Desterrados. nisearch.com/files/pdf/desterrados-alfredo-molano-pdf. 
- MUÑOZ, M. R. (2008). Necesidades educacionales y desplazamiento forzoso en Colombia”. En Revista Migración e Integración. No. 70. DVV International. Publicaciones Recuperado desde http://www.iiz-dvv.de/index. php?article_id=728\&clang=3

- OXFAM (junio de 2012). La cuenta regresiva. Un atraco a mano armada. Cómo la falta de regulación del comercio de armas está paralizando el desarrollo. Recuperado de Informe de Oxfam desde http://www.oxfam. org/sites/www.oxfam.org/files/tb-development-arms-trade-treaty-130612-es_0.pdf

- PIZARRO, N. (autor) y JIMÉNEZ, T. (asesor) (2008). El desplazamiento humano en Colombia: ¿Disminuye o aumenta? Trabajo de curso máster: Globalización, Desarrollo y Cooperación. Universidad de Barcelona. Facultat de Ciéncies Económiques. Recuperado de http://www.observatori.org/documents/Desplazamiento_humano_en_Colombia.pdf

- RÍOS, M. (2009). Diagnóstico de cobertura educativa. Recuperado de Secretaría de Educación de Santiago de Cali desde http://www.slideshare.net/kike7802/diagnstico-cobertura-sem-cali

- PAREDES, C. (5 de mayo de 2011). 10 puntos clave de la ley de víctimas. Recuperado de revista Semana desde http://www.semana.com/nacion/articulo/diez-puntos-clave-ley-victimas/239330-3

- UNESCO. (2010). Informe de seguimiento de la EPT en el mundo. Llegar a los marginados. Resumen. Recuperado el 06 de diciembre de 2012 desde http://unesdoc.unesco.org/images/0018/001865/186525s.pdf

- UNESCO. (2011). Aspectos más sobresalientes del informe 2011. Informe de seguimiento de la EPT en el mundo. Ediciones UNESCO. Recuperado el 06 de diciembre de 2012 desde http://unesdoc.unesco.org/ images/0019/001911/191186s.pdf

- W Radio (21 de mayo de 2013). 10:09 - 10:20. El personero de Cali, Andrés Santamaría, se refiere al desplazamiento en el Distrito de Aguablanca. Recuperado desde http://www.wradio.com.co/escucha/archivo_de_audio/personero-de-cali-andres-antamaria-habla-del-desplazamiento-en-distrito-de-aguablanca/20130521/ oir/1902216.aspx 